NBER WORKING PAPER SERIES

\title{
THE EFFECTS OF THE EMERYVILLE FAIR WORKWEEK ORDINANCE ON THE DAILY LIVES OF LOW-WAGE WORKERS AND THEIR FAMILIES
}

\author{
Elizabeth Ananat \\ Anna Gassman-Pines \\ John Fitz-Henley II \\ Working Paper 29792 \\ http://www.nber.org/papers/w29792 \\ NATIONAL BUREAU OF ECONOMIC RESEARCH \\ 1050 Massachusetts Avenue \\ Cambridge, MA 02138 \\ February 2022
}

This research received support from the California Wellness Foundation, the Duke Sanford School of Public Policy Pilot Fund, and the Population Dynamics Research Infrastructure Program award to the Duke Population Research Center (P2C HD065563) at Duke University by the Eunice Kennedy Shriver National Institute of Child Health and Human Development. Outstanding research assistance was provided by Laura Bellows, Sarah Harris and Ade Olayinka. Excellent project coordination was provided by Jennifer Copeland. Giovanna Merli and Candice Odgers provided helpful advice and support. Prior versions of this paper were presented at the Russell Sage Foundation, the Association for Public Policy Analysis and Management Fall Research Conference, and the Society for Research in Child Development Biennial Meeting. The views expressed herein are those of the authors and do not necessarily reflect the views of the National Bureau of Economic Research.

NBER working papers are circulated for discussion and comment purposes. They have not been peer-reviewed or been subject to the review by the NBER Board of Directors that accompanies official NBER publications.

(C) 2022 by Elizabeth Ananat, Anna Gassman-Pines, and John Fitz-Henley II. All rights reserved. Short sections of text, not to exceed two paragraphs, may be quoted without explicit permission provided that full credit, including $\odot$ notice, is given to the source. 
The Effects of the Emeryville Fair Workweek Ordinance on the Daily Lives of Low-Wage

Workers and their Families

Elizabeth Ananat, Anna Gassman-Pines, and John Fitz-Henley II

NBER Working Paper No. 29792

February 2022

JEL No. I18,J08

\begin{abstract}
Emeryville, CA's Fair Workweek Ordinance (FWO) aimed to reduce service workers' schedule unpredictability by requiring large retail and food service employers to provide advanced notice of schedules and to compensate workers for last-minute schedule changes. From a 1-in-6 sample of Emeryville retail and food service workers with young children (58 percent working in regulated businesses at baseline, the rest in the same industries in firms below the size cutoff for regulation), this study gathered daily reports of work schedule unpredictability and worker and family well-being over three waves before and after FWO implementation ( $\mathrm{N}=6,059$ observations). The FWO decreased working parents' schedule unpredictability relative to those in similar jobs at unregulated establishments. The FWO also decreased parents' days worked while increasing hours per work day, leaving total hours roughly unchanged. Finally, parent well-being improved, with significant declines in sleep difficulty.
\end{abstract}

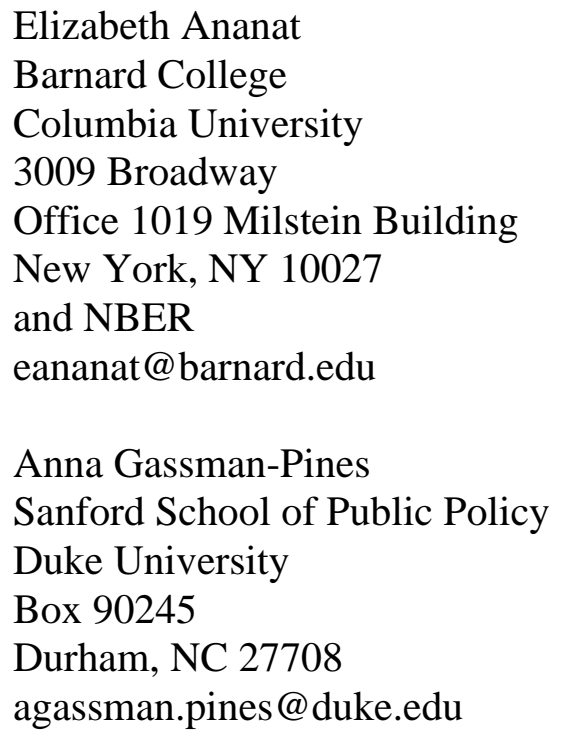

New York, NY 10027

and NBER

Anna Gassman-Pines

Sanford School of Public Policy

Duke University

Box 90245

agassman.pines@duke.edu

John Fitz-Henley II

Sanford School of Public Policy

Duke University

Durham, NC 27510

john.fitz.henley@duke.edu 
Ananat, Gassman-Pines, \& Fitz-Henley II - Effects of Emeryville Fair Workweek Ordinance - 1

Even prior to the COVID-19 pandemic, low-income families were grappling with a work landscape that had changed dramatically over the last half century. Pressures of globalization and trade, and automation, led to job destruction in many industries, particularly those such as manufacturing that in the past led to stability for less-educated workers. In their place came service work, with lower wages and more unstable employment and hours (Autor, Dorn et al. 2013). At the same time, earnings volatility increased across socio-economic levels, most markedly among lower-income people (Gottschalk and Moffitt 2009, Dynan, Elmendorf et al. 2012, Morduch and Schneider 2017). These features of work left families with high and increasing levels of instability and unpredictability in work and earnings.

Even among stably employed service-sector workers, working parents faced additional forms of uncertainty. Managerial innovations have changed the daily operations of retail and food service firms such that service workers experience great daily uncertainty in both pay and hours. For example, the managerial tactic of "on-call scheduling," in which employers facing variable customer demand minimize labor costs by requiring workers to be available for work but not compensating them for their availability if they are not needed, introduces significant unpredictability into workers' days. By increasing uncertainty, on-call scheduling practices, in addition to last-minute schedule changes and shift cancellations, may increase parents' difficulties in balancing work and family demands. That type of schedule unpredictability has been shown to be very common among low-wage workers (Lambert, Fugiel et al. 2014, Schneider and Harknett 2019, Ananat and Gassman-Pines 2021). Previous work has also established that, conditional on family fixed effects, days with schedule unpredictability lead to worse worker health than days in which work schedules go as expected (Ananat and Gassman-Pines 2021).

Partially in response to concerns about the harms to workers and families from schedule unpredictability, in the last 10 years governments at various levels across the United States have begun considering new regulations to limit unpredictability and compensate workers when it occurs. This paper, based on data collected prior to the pandemic, builds on the emerging research on the effects of such policy changes by examining the effects of the 2017 Fair Workweek Ordinance (FWO) in Emeryville, 
Ananat, Gassman-Pines, \& Fitz-Henley II - Effects of Emeryville Fair Workweek Ordinance - 2

CA, on working parents' work schedules, and worker and family well-being. While the context of lowwage work has shifted in the wake of the pandemic, understanding the challenges families were facing prior to its onset can help us understand how to restructure employment policies going forward.

We focus on a highly policy relevant group of workers: parents with young children. In so doing, this study is the first to provide evidence of the effects of a local policy aimed at deterring work schedule unpredictability on working parents' schedules and on worker and family well-being. To do so, this study used a novel sample recruitment strategy with an innovative survey data collection protocol, daily surveys using short message service (SMS) text messages, over three waves of data collection. This study is also the first to investigate this type of policy change in Emeryville, adding to ongoing work in Seattle and Oregon to build the base of knowledge about how schedule stability laws affect working families.

We recruited nearly 100 Emeryville hourly service workers with young children, a 1-in-6 sample of the universe of affected workers, using venue-time sampling, and surveyed them daily for 30 days over each of three study waves, all prior to the onset of the pandemic (2017-2018). This approach allowed us to identify how the work and family experiences of affected workers changed after the FWO, relative both to their experiences at baseline and to the experiences of workers who were otherwise similar but worked for Emeryville businesses that fell below the FWO's size thresholds.

\section{Work Schedule Unpredictability}

Recent surveys of U.S. workers underscore the ubiquity of a variety of different types of schedule precarity, including schedule instability and unpredictability, among low-wage workers. For example, using the NLSY, researchers found that 41 percent of workers receive notice of their schedules only one week ahead of time or less (Lambert, Fugiel et al. 2014). Fluctuations in work hours are also substantial, with almost 75 percent reporting fluctuations in the number of hours they worked per week over the last month. Similarly, a survey of hourly workers in large retailers found that 60 percent of workers have variable hours and that 60 percent of workers have less than two weeks' notice of their work schedules (Schneider and Harknett 2019). In Emeryville, the vast majority, 87 percent, of a representative sample of 
Ananat, Gassman-Pines, \& Fitz-Henley II - Effects of Emeryville Fair Workweek Ordinance - 3

parents with young children reported some unanticipated work schedule change during a one-month period, with 58 percent of parents reporting at least one canceled shift (Ananat and Gassman-Pines 2021).

Estimates suggest that about one in six hourly workers has a young child (Schwartz, Wasser et al. 2015), and prior research has established that schedule unpredictability is associated with worse worker and family well-being. Surveys of low-wage workers at a single point in time have shown that those with more unstable schedules report more psychological distress, worse sleep quality, and more parenting stress (Schneider and Harknett 2019). Unstable and unpredictable work schedules are also correlated with lower-quality parent-child interactions (Henly, Shaefer et al. 2006) and increased work-life conflict (Luhr, Schneider et al. this volume, Henly and Lambert 2014).

Research focusing on day-to-day variation in work schedules underscores the negative effects on workers and their families from unanticipated work schedule changes. In Emeryville, instances of work schedule unpredictability on any given day were related to worse daily mood and sleep quality for working parents (Ananat and Gassman-Pines 2021). Similarly, research has shown that on days when parents are "on-call" for work hours, they reported increased daily negative mood (Bamberg, Dettmers et al. 2012, Dettmers, Vahle-Hinz et al. 2016) and worse daily sleep quality (Härmä, Karhula et al. 2018, Sprajcer, Jay et al. 2018) than days when they are not "on-call."

Fewer prior studies focused on day-to-day variability in work schedules have examined the effects of work schedule unpredictability on other aspects of daily family wellbeing beyond parent mood and sleep quality. However, a related literature shows that daily parenting behaviors and child well-being were affected by daily nighttime work hours, with nighttime hours related to less daily parent time spent together with adolescent children, and harsher interactions between parents and children in early childhood (Gassman-Pines 2011, Lee, Davis et al. 2017). Increased parental nighttime work also led to less positive daily child behavior among preschool-aged children (Gassman-Pines 2011).

The findings from studies examining daily variation in work schedules are consistent with those from cross-sectional studies. Those examining daily variation, however, are able to use family fixed effects to control for all measured and unmeasured stable differences between families that might be 
Ananat, Gassman-Pines, \& Fitz-Henley II - Effects of Emeryville Fair Workweek Ordinance - 4

related to both work schedule unpredictability and family wellbeing. The research focused on withinfamily variation from day to day cannot be biased by between-family differences, such as parental personality or motivation. Thus, taken together, the evidence suggests that schedule unpredictability is not only correlated with worse outcomes for workers and their families, but actually causes worse well-being.

\section{Policies to Regulate Service Workers' Schedules}

Regulation and legal standards played a large role in shaping today's workplaces, e.g. through minimum wages and workplace safety requirements, and led to current U.S. norms around schedules, such as the 8-hour workday. But in recent years, labor-market regulation has paid little attention to schedules, despite dramatic shifts in the nature of scheduling practices. While earlier schedule regulations focused on preventing employers from extracting too much labor from workers, many workers today instead fear unpredictability in work and the instability in earnings that results. In response to research demonstrating links between unpredictable work schedules and harm to workers, and due to concerted labor organizing efforts (Ananat, Gassman-Pines et al. 2020), policymakers in localities and states have passed new regulations related to service workers' schedules. These policies represent an innovational shift for local labor regulation and have been passed in Emeryville, CA, Chicago, New York City, Philadelphia, San Francisco, Seattle, and the state of Oregon. Each of the policies are unique but largely share the same general features. In particular, they require large employers to provide advanced notice of work schedules to their hourly workers and to compensate workers if schedules subsequently change.

\section{Emeryville, CA's Fair Workweek Ordinance}

Passed in early 2017, the Emeryville Fair Workweek Ordinance (FWO) aims to stabilize schedules of hourly retail and food-service workers with several provisions. First, hourly workers must receive two weeks' advanced notice of their schedules. Second, workers have the right to decline previously unscheduled hours without retaliation if they are given less than two weeks' notice of hours. Third, workers are eligible for compensation for schedule changes that occur within two weeks and, in particular, for "stability pay" of up to 4 hours or half of a shift paid when a shift is cancelled, with the amount of pay increasing the closer to the shift the cancellation is made. Fourth, the FWO gives workers 
Ananat, Gassman-Pines, \& Fitz-Henley II - Effects of Emeryville Fair Workweek Ordinance - 5

the right to decline hours if they are within 11 hours of the previous shift, and workers are to be paid time and a half for shifts that fall within 11 hours of each other (so-called "clopenings").

The provisions of the Emeryville FWO apply to "large" retail and food service employers, defined as more than 55 employees globally for retail employers and both more than 55 employees globally and 20 or more employees in Emeryville for food service employers. These cutoffs mean there is some arbitrariness to which firms are treated: the large international sandwich chain Subway, for example, has fewer than 20 Emeryville employees and is untreated, while some local, single-location stores and restaurants have more than total 55 employees and are treated.

The Emeryville FWO was implemented in two phases. Beginning on July 1, 2107, the ordinance officially became effective and the city initiated a so-called "soft roll-out." During the soft roll-out, the city investigated complaints but did not impose fines against employers who were not compliant. They also held employer- and employee-focused forums to educate stakeholders on the ordinance's provisions and created and disseminated written educational materials. Beginning on January 1, 2018, the city began the full enforcement of the ordinance, including fines for non-compliance. Enforcement of the ordinance is primarily conducted via an employee-driven complaint system. If employers are found to have violated the ordinance, they can be fined up to $\$ 500$ per violation and $\$ 1,000$ for each employee retaliated against.

\section{Preliminary Evidence on Effects of Scheduling Policies}

Emerging research from Seattle and Oregon sheds light on the effects of such policies on workers, as well as the role of managers in policy implementation. In terms of effects on workers, an evaluation of workers with a range of family statuses showed significant changes in workers' schedules after the implementation of the Seattle policy. In particular, in the first year of implementation, the Seattle policy increased the share of workers receiving advanced notice of their work schedule and the share of workers receiving predictability pay when their hours were changed (Harknett, Schneider et al. 2019). In the second year of implementation, addition benefits were observed, including a reduction in last-minute schedule changes and improved worker well-being as measured by increases in overall happiness and self-reported sleep quality (Harknett, Schneider et al. 2021). Consistent with the Seattle findings, an 
Ananat, Gassman-Pines, \& Fitz-Henley II - Effects of Emeryville Fair Workweek Ordinance - 6

evaluation of the early implementation of Oregon's statewide policy also revealed that the majority of workers received advance notice of their schedule (Loustaunau, Petrucci et al. 2020).

These results generally align with studies that have focused on front-line managers as the conduits for policy implementation on behalf of employers. One year after policy implementation, managers in Seattle, for example, largely reported giving workers the required 14 days advanced notice of their shifts and following rules around shift cancellations, suggesting that implementing some of the Seattle law's provisions were relatively straightforward (Haley and Lambert 2021). Employers struggled, however, with implementing other aspects of the law: Managers reported lower levels of compliance with rules around extending shifts and offering additional hours to current employees before hiring new ones. Similar patterns of results were reported by managers in Oregon (Loustaunau, Petrucci et al. 2020). In Oregon, an additional provision enabling managers to maintain voluntary waitlists facilitated frequent last-minute changes, making implementation easier for the employer but reducing the law's reach from employees' perspectives. Although the full set of costs and benefits to employers of these types of scheduling regulations is not yet known, related research suggest that employers could expect to see improvements in worker productivity and sales. A randomized experiment of a schedule stability intervention in retail stores showed such improvements in productivity and sales (Williams, Lambert et al. 2018, Kesavan, Lambert et al. 2020). Other research also suggest that improved work hours predictability leads to increased productivity (Hashemian, Ton et al. 2020).

\section{The Current Study}

With only a limited set of localities passing scheduling regulations, evaluations of policy change in each locality are crucial to building the base of knowledge about how such regulations affect workers and families. This study addresses this need by providing evidence on the effects of the scheduling regulations implemented in Emeryville, CA and by focusing on a highly policy-relevant population that has not been the focus of work investigating the effects of scheduling regulations in other jurisdictions, parents of young children.

\section{Identification}


Ananat, Gassman-Pines, \& Fitz-Henley II - Effects of Emeryville Fair Workweek Ordinance - 7

Our main identification strategy is a difference-in-difference approach that compares over-time changes in outcomes for workers in "treatment" jobs - i.e. jobs at businesses that meet the size requirements to be regulated under Emeryville's Fair Workweek Ordinance- to changes in outcomes for workers employed at similar jobs in businesses that fall short of the size requirements. Difference-indifference designs rely on the assumption of parallel trends: the identifying assumption of our approach is that in the absence of the FWO's implementation, the over-time changes in outcomes of workers in treatment and control jobs would have moved in parallel, and therefore any deviation in treated workers' outcome trends from trends for workers in control jobs can be attributed to the effects of the FWO. Workers can and do hold multiple jobs; for outcomes that are defined at the worker-day level, such as sleep quality and interactions with the focal child, we define a worker as "treated" if they held at least one "treatment" job, even if they also held one or more control jobs. In robustness checks, we have defined treatment continuously, based on the share of hours worked at baseline in a treatment job; results are substantially similar (results available upon request).

A threat to the parallel trends assumption would occur if workers endogenously switch jobs in response to the FWO - that is, if treated jobs become more (or less) desirable due to the regulation, then workers with more advantages, e.g. those with better mental health, might switch sectors in response. Under those circumstances a simple difference-in-differences strategy, such as the type conducted using repeated cross-sectional surveys to evaluate policy changes, would inaccurately conflate compositional changes in the treated workforce due to the FWO with changes in individual worker outcomes due to the FWO. However, our panel structure avoids this problem by allowing us to combine the strengths of a difference-in-differences identification strategy with the complementary strengths of an individual fixedeffects approach: because we follow the same workers over time, we are able to include worker fixed effects and identify only changes in individual worker outcomes over time.

Another potential threat to the parallel trends assumption would occur if regulated versus unregulated businesses faced different shocks during the evaluation period, beyond those induced by the 
Ananat, Gassman-Pines, \& Fitz-Henley II - Effects of Emeryville Fair Workweek Ordinance - 8

FWO. The somewhat arbitrary and complex size cutoff for regulation—which does not coincide with thresholds for other regulations in Emeryville or with other meaningful market distinctions - makes it relatively unlikely, however, that treated and untreated firms will face different shocks (for example, to consumer demand or to credit access) on other dimensions over the implementation period.

\section{METHOD}

\section{Sample recruitment}

Individuals were eligible for this study if they worked in an hourly position in Emeryville and had a child between ages 2 and 7. Recruitment occurred in May 2017, after the passage of FWO but prior to its enactment. We used a venue-based sampling approach to recruitment. For this purpose, we secured from the City of Emeryville a complete list of retail and food service businesses in the city. Using this list, we constructed a sampling frame of venue (business) day-time units (VDTs), randomly selected VDTs, and identified and recruited eligible individuals present in those VDTs (Muhib, Lin et al. 2001). We approached workers at each business, determined their eligibility, and asked those workers to direct us to any other currently present employee with a young child. Across VDTs, we entered each business in the area at least once, talking with over 600 workers, including at least one from each retail or food establishment in the city. We estimated, based on recent surveys of hourly retail and food service workers (Schwartz, Wasser et al. 2015), that about 15 percent of the 3,743 Emeryville hourly retail and food service workers have a young child, suggesting an eligible population of 561 workers. Of these, we talked with 170, an estimated 30 percent of eligible workers. We successfully recruited 96, or 56 percent, of the eligible workers we contacted. Our sample, although small in absolute size, reflects a substantial 1-in-6 sample of the universe of Emeryville retail and food workers with a young child. Importantly, the initial sample was balanced across: 1) retail and food firms that meet threshold local and global employment levels and are subject to regulation from the FWO and 2) otherwise similar control firms below those thresholds, which are exempt from the FWO. 
Ananat, Gassman-Pines, \& Fitz-Henley II - Effects of Emeryville Fair Workweek Ordinance - 9

\section{Procedure and analysis sample}

At the beginning of the study, respondents were asked about their demographics, health and wellbeing, work history, each job's hourly wage and whether it is tipped, and reports on children. Then, every day for 30 consecutive days, respondents reported on that day's work and family experiences via SMS text message. Daily survey completion rates among participants in the initial wave were very high: 61 percent of participants completed 100 percent of the daily surveys and 89 percent completed the majority (i.e. more than 15), providing substantial within-person variation for analysis.

We contacted the sample again two times: in the Fall of 2017 during the "soft roll-out" enforcement phase of FWO implementation (wave 2) and in the spring of 2018 during the full enforcement phase of FWO implementation (wave 3). Of the initial 96 participants, 76 participated in wave 2; 71 participated in wave 3 . At each wave, we gathered information about changes in workers' jobs and job characteristics and then again collected reports on the day's work and family experiences via SMS text message for 30 consecutive days. In wave 2, daily participation was higher than in wave 1: 74 percent of participants completed 100 percent of the 30 daily surveys and 98 percent completed the majority of the daily surveys. In wave 3, daily participation was higher than in wave 1 or wave 2: 80 percent of participants completed 100 percent of the daily surveys and 99 percent completed the majority.

Participant compensation was structured to incentivize completion of all 30 daily surveys within each wave. In waves 1 and 2, participants received $\$ 1.00$ for each survey completed, with bonuses of $\$ 7$ and $\$ 10$ offered for each week with 7 completed surveys, respectively. In wave 3, participants received $\$ 1.20$ for each survey completed with a bonus of $\$ 12$ for each week with 7 completed surveys. An additional completion bonus for those who answered all 30 daily surveys was also offered: $\$ 20$ in wave 1 , \$25 in wave 2 and $\$ 30$ in wave 3.

Our analysis sample for this study included all individuals who participated in at least one of the post-FWO implementation follow-up waves ( $\mathrm{N}=78$ parents; $\mathrm{N}=\sim 6,000$ person-days for analysis). On average, our analysis sample provided 86 days of survey responses across the waves of data collection. 
Ananat, Gassman-Pines, \& Fitz-Henley II - Effects of Emeryville Fair Workweek Ordinance - 10

All survey materials used for this study were available in both English and Spanish. All aspects of this study were approved by the Duke University Institutional Review Board (protocol \#2017-0053).

\section{Measures}

Daily schedule unpredictability was characterized along a number of dimensions. We asked a series of questions about up to three jobs per respondent, based on the number of jobs reported at the initial interview for each wave. For each job, respondents were asked whether they worked that day, and if so: when they started and stopped working and whether their hours worked were their originally scheduled hours. If not, they provided their originally scheduled hours. Thus, for each day that a respondent worked at a given job, we measure whether their hours worked deviated from their originally scheduled hours at that job. Further, if respondents did not work at a given job on a given day, they were asked if they were originally scheduled to work. Thus, for each day we measure whether a respondent had

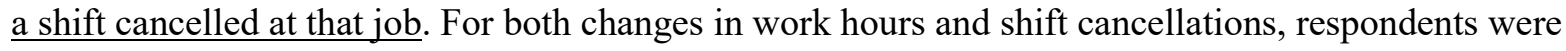
asked when they found out about the change: less than one hour before the shift start time; more than one hour before the shift start time, on the day of the shift; the night before; or earlier. Those who gave any response other than earlier about either a change in hours or a shift cancellation were coded as having a last-minute work schedule change at that job on that day.

To find surprise shifts, we looked at responses to the question about originally scheduled hours. In that space, many respondents offered context, stating that they were off, weren't scheduled for that day, or offering hours on the next day (e.g. on Monday saying that they were scheduled to work Tuesday). In any of these cases, we classified this as a surprise shift, rather than a change in hours. Finally, surprise shifts, along with changes in hours and canceled shifts, were combined to create an additional measure that indicates whether the respondent had any kind of schedule change at that job on any given day.

Because information was provided about each job on each day, it was possible to examine work schedule unpredictability both by job and by day. For all outcomes discussed above, the unit of analysis was the person-job-day. 
Ananat, Gassman-Pines, \& Fitz-Henley II - Effects of Emeryville Fair Workweek Ordinance - 11

Daily family and child well-being outcomes were measured as described below. Daily mood was measured with an item that asked respondents how much of the time they felt fretful, angry, irritable, anxious, or depressed on a three-point scale from all of the time to none of the time. This question was modified from a question with a four-week recall period from the Health Utilities Index (HUI) (Furlong, Feeny et al. 2001, Horsman, Furlong et al. 2003). The single item has been validated as a daily measure of negative mood as it is positively correlated with daily stressors, including daily food insecurity (GassmanPines and Schenck-Fontaine 2019) and daily work schedule disruptions (Ananat and Gassman-Pines 2021); it increased substantially when COVID-19 restrictions were put into place (Gassman-Pines, Ananat et al. 2020). A dichotomous indicator was created equal to 1 for those who answered Some of the time or All of the time and 0 for those who answered None of the time.

Daily perceived negative sleep quality was measured with a single item used in other daily survey studies (George, Rivenbark et al. 2019), asking: “How well did you sleep last night?” Answers were on a 10-point scale from really badly to really well. We treat self-reported sleep quality as a measure of daily well-being, as perceived sleep quality is associated with daily affect (Bower, Bylsma et al. 2010). The sleep quality measure was reverse-coded so that higher numbers indicated worse perceived sleep quality. This measure has been validated, as it is correlated in expected directions with negative and positive daily mood, daily self-esteem (George, Rivenbark et al. 2019) and daily work schedule disruptions, a daily stressor (Ananat and Gassman-Pines 2021).

Daily parent-child interactions was measured with two questions: "Did you punish your child today?" and "Did you lose your temper with your child today?" Dichotomous indicator variables were set equal to 1 if the parent responded Yes and 0 if the parent responded No. Both of these measures have been validated as they were both positively correlated with daily disruptions to school and care during the COVID-19 pandemic (Gassman-Pines, Ananat et al. 2021).

Finally, daily child behavior was measured with two items. Daily child uncooperative behavior was measured with a single item asking: "How much was your child uncooperative today?" Answers on a four-point scale included: Not at all, Just a little, Some, and A lot. This question was modified from an 
Ananat, Gassman-Pines, \& Fitz-Henley II - Effects of Emeryville Fair Workweek Ordinance - 12

item in the Inattention/Overactivity with Aggression Conners Rating Scale (Loney and Milich 1982), which asks parents to rate how much the adjective describes their child "at this time." Daily child worry was measured with a single item asking: "How much did your child appear to be sad or worried today?" Answer choices on a four-point scale included: Not at all, Just a little, Some, and A lot. This question was modified from an item in the Preschool Behavior Questionnaire (Behar and Stringfield 1974), which asks parents to rate how much the child exhibits each behavior.

For both child behaviors, prior research has demonstrated the reliability and validity of multi-item scale versions adapted for measuring daily externalizing and internalizing behavior problems (GassmanPines 2015). In the current study, single items were used to reduce respondent burden and attrition. Dichotomous indicator variables were set equal to 1 if the parent responded Some or $A$ lot and 0 if the parent responded Not at all or Just a little. These single-item measures have been validated as they were both positively correlated with daily disruptions to school and care during the COVID-19 pandemic (Gassman-Pines, Ananat et al. 2021).

Job type (e.g., treatment vs. control) was categorized as follows: for each of up to 3 jobs reported by a respondent, a job was coded as a "treatment" job if it was an hourly position at a venue listed by the City of Emeryville as regulated under the FWO. A job was coded as a "control" job if it was at a retail or food establishment in Emeryville that was listed by the City as not covered under the FWO, or if it was outside of Emeryville or outside of retail and food. Workers were categorized as in the treatment group if they had at least one treatment job; otherwise, they were classified as in the control group. All respondents had at least one hourly position in food service or retail in Emeryville, but respondents could also have additional jobs outside of Emeryville, outside of food or retail, and/or paid other than hourly.

\section{Analytic strategy}

To evaluate the job-experience relationships of interest, i.e. effects on schedule unpredictability, the following equation was used:

$$
Y_{i j t}=\beta_{0}+\beta_{1} * \text { Treat }_{i j} * \text { After }_{t}+\beta_{2} * \text { After }_{t}+\beta_{3} * \text { Treat }_{i j}+\psi_{i j}+\tau_{t}+\epsilon_{i j t}
$$


Ananat, Gassman-Pines, \& Fitz-Henley II - Effects of Emeryville Fair Workweek Ordinance - 13

for outcome $Y$ for person $i$ in job $j$ on day $t$, where $\psi$ represents a vector of individual-by-job fixed effects and $\tau$ is an indicator for whether day $t$ falls on a weekend. Previous research shows that both work and home experiences differ dramatically between weekends and weekdays for workers in these types of jobs (Ryan, Bernstein et al. 2010, Shrout, Bolger et al. 2010, Gassman-Pines 2011, GassmanPines, Ananat et al. 2020, Ananat and Gassman-Pines 2021). Because of idiosyncratic variation in individual start days, respondents experience different numbers of weekend days, which would, if we simply averaged across days within person and wave, lead to greatly increased noise in our estimates.

Treat $_{i j}$ is an indicator variable equal to one if job $j$ was at a treated firm subject to FWO regulations, and zero otherwise. We measure job-experience outcomes (hours changes, surprise shifts, and cancelled shift) at the person-job-day, rather than person-day, level because the variation in those outcomes exists at the person-job-day level. For example, we measure canceled shifts at the person-jobday level because a worker with two jobs might have had a shift canceled at one job on a given day, while on the same day their shift at another job was not canceled. As we are interested in whether the policy affects scheduling practices such as this, and as the policy can, in some cases, affect one of a respondent's jobs but not the other, examining job outcomes separately is scientifically appropriate. Note, however, that most respondents have only one job (Table 1), so this has only a minor effect on our sample size. After $_{t}$ is an indicator variable equal to one if day $t$ falls during the post-implementation period, and zero otherwise. The definition of the post-implementation period is somewhat ambiguous because Emeryville began implementation with a "soft roll-out," as discussed above. To accommodate this ambiguity, our main results include three separate approaches to defining pre- and post: (1) base estimates only on pre-implementation (Wave 1) and full enforcement (Wave 3) data, with full enforcement Wave 3 observations defined as post-implementation; (2) include all observations and define both soft roll-out and full-enforcement observations as post-implementation; and (3) include all observations, and estimate:

$$
\begin{gathered}
Y_{i j t}=\beta_{0}+\beta_{1} * \text { Treat }_{i j} * \text { Wave }_{t}+\beta_{2} * \text { Wave }_{t}+\beta_{3} * \text { Treat }_{i j} * \text { Wave }_{t} \\
+\beta_{4} * \text { Wave }_{t}+\beta_{5} * \text { Treat }_{i j}+\psi_{i}+\tau_{t}+\epsilon_{i j t}
\end{gathered}
$$


Ananat, Gassman-Pines, \& Fitz-Henley II - Effects of Emeryville Fair Workweek Ordinance - 14

This specification allows us to estimate the effect of the FWO during the soft roll-out (represented by the estimated value of the coefficient $\beta_{1}$ ) separately from the effect of the FWO during full enforcement (represented by the estimated value of the coefficient $\beta_{3}$ ), and we report the estimates for both effects in our main results.

Worker and family well-being (worker sleep quality and mood, parenting behaviors, and child behavior) exist only at the person-day level, evaluated using the following equation:

$$
Y_{i t}=\beta_{0}+\beta_{1} * \text { Treat }_{i} * \text { After }_{t}+\beta_{2} * \text { After }_{t}+\beta_{3} * \text { Treat }_{i}+\psi_{i}+\tau_{t}+\epsilon_{i t}
$$

for outcome $Y$ for person $i$ on day $t$. Treat $t_{i}$ is equal to one if person $i$ had at least one treatment job, and equal to zero otherwise. All other variables are as defined above, and a parallel specification shift was made to estimate our third approach to modeling soft roll-out and full enforcement effects.

In addition to fixed effects for each respondent, we cluster our standard errors at the person level, to reflect the fact that observations for a given respondent across jobs, days, and waves are not independent of one another. Clustering of standard errors relaxes the assumption that errors are independent and identically distributed and allows for errors within a cluster (in this case, a person) to instead be arbitrarily correlated. With 78 respondents in our analytical sample, we have a large enough sample to estimate person-fixed effects, use our average of 86 observations per respondent to estimate standard errors clustered on person, and then to estimate effects of the policy. ${ }^{1}$

\section{RESULTS}

\section{Descriptive Results}

Table 1 reports descriptive results at baseline for the analysis sample, overall and separately for the treatment and control groups (defined at Wave 1). Respondents were, on average, 30 years old, with

\footnotetext{
${ }^{1}$ Our highly racially diverse sample means, however, that we have a small number of respondents of each raceethnic identity. Estimates with fixed effects and clustering, regardless of how large their total N, do not exhibit large-sample properties when they include only a small set of clusters (Angrist \& Pischke 2009), meaning our sample is unfortunately not adequate to estimate such models.
} 
Ananat, Gassman-Pines, \& Fitz-Henley II - Effects of Emeryville Fair Workweek Ordinance - 15

11.7 years of education, and had their first child at age 24 . The majority, 86 percent, of the sample identified as female. Just under 30 percent had ever been married. They were racially and ethnically diverse: 31 percent were Hispanic (of any race); 45 percent were non-Hispanic Black; 8 percent were non-Hispanic White; 8 percent were non-Hispanic Asian-American; 1.2 percent were non-Hispanic Native American; and 7.1 percent were non-Hispanic multiracial. On average, they held 1.13 jobs. Respondents' household income averaged $\$ 2,795$ per month. The majority of respondents lived with at least one other adult: 58 percent lived with a romantic partner, and 21 percent lived with a parent. On average respondents had 1.8 children. Fifty-eight percent held at least one treatment job.

Financial strain was common among respondents. Over one in five reported generally not having enough money to make ends meet, with another half reporting generally having just enough. Nearly twothirds of respondents doubted they could access funds to pay for a $\$ 1000$ emergency. About the same number had to borrow from friends or family in the past year to make ends meet, while 37 percent had applied for government assistance.

Not surprisingly given all these stressors, respondents reported mental health challenges as well. More than one in four reported finding it "often or always" difficult to relax, and one in ten "often or always" felt downhearted or blue. Similarly, 21 percent of respondents reported that their focal child was often "somewhat or very" worried, and 10 percent that their focal child was often "somewhat or very" unhappy, depressed, or tearful.

Across most characteristics, baseline characteristics were well-balanced across treatment and control. Among 24 characteristics, two were significantly different between the groups at the 10 percent level, consistent with chance. This balance suggests that, among hourly service workers with young children, there is little selection on observables into treatment (larger firm) versus control (smaller firm) jobs.

The exception to this balance was differences in child care arrangements, with those in treatment jobs less likely to access formal childcare and more likely to instead rely on relative care, and for more hours per week. We interpret these differences as a reflections of the jobs themselves rather than selection 
Ananat, Gassman-Pines, \& Fitz-Henley II - Effects of Emeryville Fair Workweek Ordinance - 16

into them; as shown in Figure 1, at baseline treatment jobs were more unpredictable, which, as documented in other work (Luhr et al., this volume) makes use of formal childcare more challenging. Note, however, that even if the difference in childcare suggested imbalance on unobservables between the treatment and control groups, difference-in-difference designs do not require baseline equality between treatment and control; rather, we instead rely on the much weaker assumption of parallel trends.

Table 2 summarizes all daily work and well-being outcomes across people, jobs, and waves. Because there were significant differences in these measures across race, we report both overall means and means for non-Hispanic Blacks, non-Hispanic Whites, non-Hispanic Asian-Americans, and Hispanics (of any race). Overall, some type of schedule change was made on nearly 11 percent of job-days, with a significantly greater share of days with a change among Asian-American respondents (17 percent) and a significantly lower share among White respondents ( 8 percent). The majority of schedule changes were last-minute, with less than 24 hours' notice; White respondents were less likely to experience changes at the last minute (4.7 percent of days versus 7.0 percent for the sample overall).

Among the types of schedule changes, a change in work hours was the most common, occurring on 5.4 percent of days on average but at almost twice that frequency, 10.3 percent of days, among AsianAmericans. Surprise shifts were the least common type of schedule change, occurring on less than 1 percent of days, with no differences across groups. Across all waves, respondents worked on about 55 percent of job-days; Asian-Americans and Hispanic respondents were more likely than average to work on a given day. The average shift length on any given work day was 7.1 hours, but was higher for Whites, at 7.4 hours, and lower for Asian-Americans, at 6.7 hours.

Finally, in terms of family well-being outcomes, negative mood was fairly common, with respondents overall reporting negative mood on 42 percent of days. White respondents reported significantly more days with negative mood (60 percent of days), while Hispanic respondents reported fewer (32 percent). Sleep difficulties were greater among Whites and lower among Asian-Americans; harsh parenting behaviors were higher among Whites and Asian-Americans than among the population 
Ananat, Gassman-Pines, \& Fitz-Henley II - Effects of Emeryville Fair Workweek Ordinance - 17

overall. Black and Asian-American parents reported more days with child uncooperativeness and child worry than did the sample overall. Child behavior problems were relatively infrequent across all groups.

\section{Impacts of the Emeryville FWO}

Table 3 reports effects of the FWO on schedule disruption outcomes; given small sample sizes, we were not able to separately estimate effects of the FWO by race and ethnicity, as discussed above. Across all models, results showed that the FWO led to a decrease in any schedule change overall, with point estimates ranging from 2.5 percentage points to 5.5 percentage points, though not all point estimates reached conventional levels of statistical significance. Results from model three suggest that decreases in schedule changes occurred right away, in the soft-roll out phase of enforcement. The estimates from our third model are also presented in Figure 1, which shows that treatment jobs had more frequent schedule changes than control jobs in the pre-period, but that rates of schedule changes for the treatment jobs declined to the same level as the control jobs once the FWO was implemented. As shown in Table 3 and Figure 1, the same pattern of results was found for last-minute changes: the FWO reduced last-minute schedule changes. Again, although not all estimates reached conventional levels of statistical significance, the pattern of findings is consistent with a decline in last-minute changes following FWO implementation for the treatment jobs relative to the control jobs.

Among the types of schedule disruptions considered, we found that surprise shifts were most strongly affected by the FWO, while point estimates for changes in work hours follow a similar, but not statistically significant, pattern (Table 3). Shift cancellations were not affected by the FWO. As shown in Figure 1, treatment jobs had more frequent surprise shifts in the pre-period but rates of surprise shifts for the treatment jobs declined once the FWO was implemented, and were lower than rates in control jobs by the full-enforcement phase.

Table 4 reports effects of the FWO on daily work and hours outcomes. Results show that the FWO decreased the likelihood of working in a treatment job on any given day. The effect size was substantial, with decreases in wave three of about 12 percentage points. As shown in Figure 1, the likelihood of working in a treatment or control job on any given day were very similar prior to the 
Ananat, Gassman-Pines, \& Fitz-Henley II - Effects of Emeryville Fair Workweek Ordinance - 18

implementation of the FWO. During the post-period, the likelihood of working in a control job on any given day increased slightly while the likelihood of working in a treatment job decreased.

At the same time, however, results also showed that the FWO increased the length of shifts on work days. By the full enforcement phase, the increase in work hours was about .4 hours, on average. When combining the two effects by considering average work hours including zeroes for non-work days, the FWO did not significantly affect hours worked within a job. Workers do not appear to have increased work in non-regulated firms in response to changes in their treatment jobs, given that average work hours across all jobs were also not significantly affected by the FWO.

Finally, Table 5 reports effects of the FWO on parent and child outcomes. Considering parental well-being, the FWO decreased sleep difficulty (defined by reverse-coding and then normalizing the sleep quality responses that had been gathered using a 1-10 scale), though not all estimates reach conventional levels of statistical significance. In wave 3 , sleep difficulty decreased by nearly $.28 S D$ for those in treatment jobs, relative to those in control jobs. As show in Figure 1, those in treatment jobs experienced more sleep difficulty than those in control jobs prior to the implementation of the FWO, with sleep difficulty decreasing substantially during the full enforcement phase. Effects on daily parental negative mood were also in the negative direction, but did not reach statistical significance. We did not find any effects of the FWO on either parenting behaviors or child behavior.

\section{Robustness Checks}

We conducted a variety of robustness checks (all results available on request). First, we ran all models on a balanced panel of participants who participated in all waves, rather than only in at least one post-implementation wave. Results were substantially similar to those reported here. Second, we ran all models using initial treatment status at the person-level only. Results were in the same direction and of similar magnitude to those described here but were less precisely estimated. Third, we ran all models using a continuous definition of treatment status defined by the share of total work hours worked at a treatment job at baseline; results were substantially similar. Fourth, we ran models of hours worked dropping observations for which hours information was incomplete and had to be imputed; results were 
Ananat, Gassman-Pines, \& Fitz-Henley II - Effects of Emeryville Fair Workweek Ordinance - 19

substantially similar. Fifth, we estimated all models for demographic subgroups defined by race, ethnicity, gender, and education; unfortunately, sample sizes became too small for interpretation.

\section{DISCUSSION}

Low-income families in the $21^{\text {st }}$ century, especially those working in the service sector, faced high levels of unpredictability in work hours and pay, even prior to the onset of the COVID-19 pandemic and its disruptions to the labor market. Anecdotally, there seems to be little possibility that the pandemic and its related economic dislocations have improved predictability. Local regulations aimed at reducing unpredictability in work schedules are a new innovation in labor policy that were gaining traction in many localities, and one state, in the United States prior to the pandemic, but little is known about such policies' effects and, therefore, whether predictability for low-income families will be improved by encouraging more localities to adopt such policies going forward. Emeryville, CA is one of only a handful of localities that has passed such an ordinance. This paper, thus, addresses a gap in the literature by being the first to examine the effect of Emeryville's Fair Workweek Ordinance on working parents and their families.

We find that the Fair Workweek Ordinance (FWO) succeeded in reducing schedule unpredictability for workers with young children, particularly changes in start and end times of shifts and surprise shifts. The FWO also decreased the number of workdays significantly for treated workers in our sample, while increasing the hours worked on workdays and leaving total work hours insignificantly affected. It is possible that these changes were concentrated among those, like our sample, with caregiving responsibilities, and represent a re-assignment by employers of short, unpredictable, or otherwise difficult shifts from such workers to workers without caregiving responsibilities, for whom such marginal shifts are less costly. Future work should examine effects of schedule predictability legislation on different populations of workers.

The regulatory success of the FWO translated into some health benefits for workers in regulated jobs, in particular, improved sleep quality. Thus, even with a relatively small sample size, this paper thus presents important initial evidence that this type of policy change can affect work schedule 
Ananat, Gassman-Pines, \& Fitz-Henley II - Effects of Emeryville Fair Workweek Ordinance - 20

unpredictability among working parents, and can do so by impacting individual workers rather than merely by shifting sector composition.

These findings are notable in the context of the remarkable changes in work in the last half century, with increasing instability and unpredictability in employment, hours, and pay, especially for workers with less access to formal higher education. Historically, regulations played a large role in shaping today's workplaces, for example through minimum wages and anti-discrimination policy, and also created the current U.S. norms around scheduling, including the 8-hour workday and the weekend. But in recent years, regulation of the labor market has focused little attention on scheduling, despite the fact that the nature of work schedules has been shifting dramatically. In particular, while the earlier generation of scheduling regulation concentrated on preventing employers from extracting too much labor from workers, many of today's workers fear instead too much variability and unpredictability in work and pay. That is, recent concerns focus on employers shifting the risk of variable customer demand from themselves to their employees, by giving workers neither hours nor pay when demand is unexpectedly low. Indeed, the Emeryville ordinance studied in this paper was passed in response to such concerns.

Our results show that the Emeryville FWO decreased schedule changes and, in particular, lastminute schedule changes. These impacts are notable because these are the dimensions of schedule changes that our own prior research has shown to be particularly costly for working parents and their families, in terms of reduced parental well-being (Ananat and Gassman-Pines 2021). These findings are also consistent with those from an evaluation of Seattle's secure scheduling law that examined all workers (rather than focusing on parents) and found that Seattle's law also decreased last-minute schedule changes (Harknett, Schneider et al. 2021). This convergent evidence suggests that local schedule regulations can be a fruitful path for addressing unpredictability in work schedules for low-income families. Importantly, we observe these changes immediately after the law was passed, during the "soft roll-out" phase of enforcement. Although the City only began fining non-compliant businesses during full enforcement, our results suggest that simply having a law go into effect is a powerful change that leads at least some firms to comply, even if they are not at risk of being fined or penalized. 
Ananat, Gassman-Pines, \& Fitz-Henley II - Effects of Emeryville Fair Workweek Ordinance - 21

We also find that changing scheduling practices through this local ordinance leads employers in covered firms to reduce the number of shifts that employees work. However, the FWO leads to increased hours for parents on the days when they do work, leaving no significant changes in average hours worked. Given the fixed costs of working on a given day, including making child care arrangements and commuting, it is plausible that on net these scheduling changes made workers better off. Consistent with this possibility, the net effect of the Emeryville FWO was to improve workers' well-being as proxied by subjective sleep quality. Working parents, in particular, are likely to place a high value on the stability of work schedules, as stable work schedules make balancing the demands of work and family easier (Henly 2004, Henly and Lambert 2014).

The evidence related to the effects of scheduling regulation on worker sleep quality is notable for several reasons. First, these results are highly similar to those found in the Seattle evaluation; Seattle's ordinance also improved subjective sleep quality (Harknett, Schneider et al. 2021). This converging evidence underscores the role for scheduling regulation in improving workers' sleep quality. Second, service sector workers emphasize sleep disruptions and poor-quality sleep as consequences of schedule unpredictability (Human Impact Partners and Center for Popular Democracy 2016), and our own prior work in Emeryville showed these effects on a daily level (Ananat and Gassman-Pines 2021). Reductions in work schedule unpredictability may improve sleep quality for a number of reasons, including: by helping to stabilize daily routines; by facilitating circadian rhythms, which can be disrupted by unstable and unpredictable work schedules; and by reducing job strain, each of which has been linked to sleep quality (Eriksen, Bjorvatn et al. 2008, Moss, Carney et al. 2015, Kecklund and Axelsson 2016). Other aspects of work life, such as commute time, may also play a role in exacerbating links between unpredictable work schedules and worse sleep quality, as longer commutes themselves are associated with worse sleep (Petrov, Weng et al. 2018); the shift to longer work hours on fewer days may have thus contributed to better sleep by reducing total commute time.

Finally, subjective sleep quality is also a marker of well-being and an important input into both physical and mental health (Brewster, Billy et al. 1993, Bower, Bylsma et al. 2010). Worse sleep quality, 
Ananat, Gassman-Pines, \& Fitz-Henley II - Effects of Emeryville Fair Workweek Ordinance - 22

for example, is related to both heart disease in the adult population (Cappuccio, Cooper et al. 2011) and depression among parents (Park, Meltzer-Brody et al. 2013). Poor sleep quality is associated with more harsh parenting behavior (Kelly, Erath et al. 2021), and worse daily sleep quality has been found to exacerbate the effects of chronic and daily stressors on daily negative parental mood (da Estrela, Barker et al. 2018, Lillis, Hamilton et al. 2018, Mihaila and Hartley 2018). Thus, improvements in sleep quality may have the potential to lead to longer-term improvements in family functioning and child wellbeing, such as more positive parent-child interactions, reduced parental stress, and improved child behavior. Future research should investigate the mechanisms connecting unpredictable work schedules to worse sleep quality, the family well-being consequences of improved sleep quality, and moderation by other aspects of work, such as commute time. While the small population of Emeryville means we were underpowered to detect downstream effects on children's well-being even in a 1-in-6 probability sample, the implications are conceptually clear, as children are influenced and constrained by their parents' lived experiences in the labor market (Ananat, Gassman-Pines et al. 2017). Links between parental well-being and child adjustment are well established (Cummings and Davies 1994, Cummings, Keller et al. 2005, Cummings, Davies et al. 2020). Parents who are experiencing psychological distress tend to have more difficulty acting as sensitive caregivers, which can lead to increased behavior problems and other difficulties for children (Dix, Gershoff et al. 2004).

We note that our sample included only working parents with young children, a group that is particularly strongly affected by work schedule unpredictability but is not representative of all workers in the treatment firms. It is possible, for example, that workers without young children (the majority of workers) may have experienced an increase in work shifts due to the Emeryville FWO, if they were willing to add shifts on short notice. Our results are not meant to generalize to all Emeryville retail and fast food employees, but only to employees with young children, a group of a priori concern due to both their vulnerability and their relevance to public policy.

Our methodological approach, pioneered in this study, has several strengths that enhance the contribution of this work. First, although small, our use of a venue-time sampling strategy resulted in a 
Ananat, Gassman-Pines, \& Fitz-Henley II - Effects of Emeryville Fair Workweek Ordinance - 23

sample that is representative of Emeryville workers in retail or food service with a child between the ages of two and seven. Given that such a population is unrostered and difficult to enumerate, implementing a representative sampling strategy was a major innovation. Second, we followed our sample longitudinally, which avoids bias from compositional changes in the workforces of firms after they become regulated. Therefore, our results cannot be explained by, for example, covered businesses becoming more attractive to workers with better mental health after FWO implementation. Finally, work schedule disruptions were measured via daily surveys, which avoids recall bias, a problem we have shown in previous work to be sizeable in reporting the frequency of schedule changes (Ananat \& Gassman-Pines, 2021).

We do note, however, that despite our ability to follow the same representative sample longitudinally, it is still possible that endogenous sector-switching in response to time-varying worker characteristics could be driving some of our results. For example, if employment in covered businesses became more attractive post-FWO implementation, and therefore workers who experienced changes (such as becoming newly partnered and therefore better able to manage child care) that made them more desirable employees became more likely to switch into the covered sector than they would have been in the absence of the FWO, that could threaten the validity of our findings if these same changes also had direct impacts on worker well-being. The waves, however, were fielded only a few months apart, so any changes in employee characteristics, subsequent changes in employee desirability, and resulting changes in employment would have had to unfold quite quickly.

Additionally, our small overall sample size prevented us from examining subgroup effects. Understanding the heterogeneity in effects of schedule regulations for workers with different characteristics is important for future study, and will be facilitated by research with larger sample sizes. Finally, examining effects on employers was outside the scope of this study. Emerging literature would suggest that employers likely faced some challenges in implementing the law's provisions, but also that they may have benefited in terms of enhanced worker productivity and sales. Additional research should investigate effects on employers to understand the comprehensive impacts of scheduling regulations.

\section{SUMMARY AND CONCLUSION}


Ananat, Gassman-Pines, \& Fitz-Henley II - Effects of Emeryville Fair Workweek Ordinance - 24

To summarize, our results show that the Emeryville Fair Workweek Ordinance (FWO) reduced schedule unpredictability for working parents of young children, a group that has particular difficulty balancing work and family and is of policy concern. The FWO also decreased the number of work shifts, but increased shift length, leaving total work hours unchanged. The FWO also improved one measure of well-being: sleep quality. This is important initial evidence that secure scheduling policy changes can affect work schedule unpredictability among working parents, and, ultimately, these parents' well-being.

Parents working in the service sector face a myriad of challenges in balancing their work and family demands, which have plausibly only worsened in the wake of the COVID-19 pandemic. Work schedule unpredictability is a particularly salient and ongoing challenge that has been highlighted by workers, labor organizers, and social science scholars. Emeryville's law improved schedule predictability and well-being for working parents, suggesting that such laws could provide a pathway towards increasing predictability for low-income families. 
Ananat, Gassman-Pines, \& Fitz-Henley II - Effects of Emeryville Fair Workweek Ordinance - 25

\section{REFERENCES}

Ananat, Elizabeth O., and Anna Gassman-Pines. 2021. "Work schedule unpredictability: daily occurrence and effects on working parents' well-being." Journal of Marriage and Family 81(1): 10-26.

Ananat, Elizabeth O., Anna Gassman-Pines, Dania V. Francis, and Christina M. Gibson-Davis. 2017.

"Linking job loss, inequality, mental health, and education." Science 356(6343): 1127-1128.

Ananat, Elizabeth O., Anna Gassman-Pines, and Yulya Truskinovsky (forthcoming). "Increasing instability and uncertainty among low-wage workers: Implications for inequality and potential policy solutions." The Politics of Distribution. F. Rosenbluth and M. Weir. New York, Cambridge University Press.

Angrist, Joshua D. and Jörn-Steffen Pischke (2009). Mostly Harmless Econometrics. Princeton, NJ, Princeton University Press.

Autor, David H., David Dorn, and Gordon H. Hanson. 2013. "The Geography of Trade and Technology Shocks in the United States." The American Economic Review 103(3): 220-225.

Bamberg, Eva, Jan Dettmers, Hannah Funck, Birgit Krähe, and Tim Vahle-Hinz. 2012. "Effects of OnCall Work on Well-Being: Results of a Daily Survey 1." Applied Psychology: Health and Well-Being 4(3): 299-320.

Behar, Lenore, and Samuel Stringfield. 1974. "A behavior rating scale for the preschool child." Developmental Psychology 10: 601-610.

Bower, Bethanne, Lauren M. Bylsma, Bethany H. Morris, and Jonathan Rottenberg. 2010. "Poor reported sleep quality predicts low positive affect in daily life among healthy and mood-disordered persons."

Journal of Sleep Research 19(2): 323-332.

Cummings, E. Mark, and Patrick T. Davies. 1994. "Maternal depression and child development." Journal of Child Psychology and Psychiatry 35(1): 73-122.

Cummings, E. Mark, Patrick T. Davies, and Susan B. Campbell. 2020. Developmental Psychopathology

and Family Process: Theory, Research, and Clinical Implications. Guilford Publications.

Cummings, E. Mark, Peggy S. Keller, and Patrick T. Davies. 2005. "Towards a family process model of maternal and paternal depressive symptoms: Exploring multiple relations with child and family functioning." Journal of Child Psychology and Psychiatry 46(5): 479-489.

da Estrela, Chelsea, Erin T. Barker, Sarah Lantagne, and Jean-Phillippe Gouin. 2018. "Chronic parenting stress and mood reactivity: The role of sleep quality." Stress and Health 34(2): 296-305.

Dettmers, Jan, Tim Vahle-Hinz, Eva Bamberg, Niklas Friedrich, and Monika Keller. 2016. "Extended work availability and its relation with start-of-day mood and cortisol." Journal of Occupational Health Psychology 21(1): 105.

Dix, Theodore, Elizabeth T. Gershoff, Leah N. Meunier, and Pamela C. Miller. 2004. "The affective structure of supportive parenting: depressive symptoms, immediate emotions, and child-oriented motivation." Developmental Psychology 40(6): 1212.

Dynan, Karen, Douglas Elmendorf, and Daniel Sichel. 2012. "The evolution of household income volatility." The BE Journal of Economic Analysis \& Policy 12(2).

Furlong, William J., David H. Feeny, George W. Torrance, and Ronald D. Barr. 2001. "The Health Utilities Index (HUI $\left.{ }^{\circledR}\right)$ system for assessing health-related quality of life in clinical studies." Annals of Medicine 33(5): 375-384.

Gassman-Pines, Anna. 2011. "Low-income mothers' nighttime and weekend work: Daily associations with child behavior, mother-child interactions and mood." Family Relations 60: 15-29.

Gassman-Pines, Anna. 2015. "Effects of Mexican immigrant parents' daily workplace discrimination on child behavior and family functioning." Child Development 18: 1175-1190.

Gassman-Pines, Anna, Elizabeth O. Ananat, John Fitz-Henley II, and Jane Leer. 2021. "Effect of daily school and care disruptions during the COVID-19 pandemic on child behavior problems."

Gassman-Pines, Anna, Elizabeth O. Ananat and John Fitz-Henley. 2020. "COVID-19 and parent-child psychological well-being." Pediatrics 146(4). 
Ananat, Gassman-Pines, \& Fitz-Henley II - Effects of Emeryville Fair Workweek Ordinance - 26

Gassman-Pines, Anna, and Anika Schenck-Fontaine. 2019. "Daily Food Insufficiency and Worry among Economically Disadvantaged Families with Young Children." Journal of Marriage and Family. George, Madeleine J., Joshua G. Rivenbark, Michael A. Russell, Leonard Ng'eno, Rick H. Hoyle, and Candice L. Odgers. 2019. "Evaluating the Use of Commercially Available Wearable Wristbands to Capture Adolescents' Daily Sleep Duration." Journal of Research on Adolescence 29(3): 613-626. Gottschalk, Peter, and Robert Moffitt. 2009. "The rising instability of US earnings." Journal of Economic Perspectives 23(4): 3-24.

Haley, Anna, and Susan Lambert. 2021. Implementing Work Scheduling Laws: Unpacking Frontline Policymaking by Retail \& Food Service Managers. Work Family Research Network Conference. Virtual. Harknett, Kristen, Daniel Schneider and Véronique Irwin (2019). Worker impact study. Evaluation of Seattle's Secure Scheduling Ordinance: Year 1 findings. West Coast Poverty Center. Seattle, WA, West Coast Poverty Center.

Harknett, Kristen, Daniel Schneider and Véronique Irwin (2021). Seattle's Secure Scheduling Ordinance Year 2 Worker Impact Report. Cambridge, MA, The Shift Project.

Härmä, Mikko, Kati Karhula, Annina Ropponen, Sampsa Puttonen, Aki Koskinen, Anneli Ojajärvi, Tarja Hakola, Jaana Pentti, Tuula Oksanen and Jussi Vahtera (2018). "Association of changes in work shifts and shift intensity with change in fatigue and disturbed sleep: a within-subject study." Scandinavian Journal of Work, Environment and Health 44(4): 394-402.

Hashemian, Mahdi, Zeynep Ton and Hazhir Rahmandad (2020). "The Effect of Unstable Schedules on Unit and Employee Productivity." Social Science Research Network. https://ssrn.com/abstract=3839673 Henly, Julia R. (2004). "Non-standard Work and Family Life: Themes from a Qualitative Study of Lowincome Mothers Employed in the Retail Sector." Association of Public Policy Analysis and Management Fall Conference. Georgia (October 2004).

Henly, Julia R. and Susan J. Lambert (2014). "Unpredictable work timing in retail jobs: Implications for employee work-life conflict." ILR Review 67(3): 986-1016.

Henly, Julia. R., H. Luke Shaefer and Elaine Waxman (2006). "Nonstandard work schedules: Employerand employee-driven flexibility in retail jobs." Social Service Review 80(4): 609-634.

Horsman, John, William Furlong, David Feeny and George Torrance (2003). "The Health Utilities Index (HUI®): concepts, measurement properties and applications." Health and quality of life outcomes 1(1): 54. Human Impact Partners and Center for Popular Democracy (2016). Scheduling away our health: how unpredictable work hours affect health and well-being. The Center for Popular Democracy.

Kelly, Ryan J., Stephen A. Erath, Olivia Martin-Piñón and Mona El-Sheikh (2021). "Longitudinal relations between parents' sleep problems and harsh parenting." Journal of Family Psychology.

Kesavan, S., S. Lambert, Joan Williams and Pradeep Pendem (2020). "Doing Well By Doing Good: Improving Store Performance with Employee-friendly Scheduling Practices at the Gap, Inc." Social Science Research Network. https://ssrn.com/abstract=3731670

Lambert, Susan J., Peter J. Fugiel and Julia R. Henly (2014). "Precarious work schedules among earlycareer employees in the US: A national snapshot." Research brief. Chicago: University of Chicago, Employment Instability, Family Well-Being, and Social Policy Network (EINet).

Lee, Soomi, Kelly D. Davis, Susan M. McHale, Erin L. Kelly, Ellen E. Kossek and Ann C. Crouter (2017). "When mothers' work matters for youths' daily time use: Implications of evening and weekend shifts." Journal of child and family studies 26(8): 2077-2089.

Lillis, Teresa A., Nancy A. Hamilton, Sarah D. Pressman, Maisa S. Ziadni, Christina S. Khou, Lauren E. Boddy and Linzy M. Wagner (2018). "Sleep quality buffers the effects of negative social interactions on maternal mood in the 3-6 month postpartum period: a daily diary study." Journal of behavioral medicine 41(5): 733-746.

Loney, Jan and Richard Milich (1982). "Hyperactivity, inattention, and aggression in clinical practice." Advances in development and behavioral pediatrics. M. Wolraich and D. K. Rough. Greenwich, CT, JAI Press. 3: 113-147. 
Loustaunau, Lola, Larissa Petrucci, Amelia Coffey, Eleanor Lauderback, H. Elizabeth Peters, Ellen Scott and Lina Stepick (2020). Combating Unstable Schedules for Low-wage Workers in Oregon. Urban Institue.

Sigrid Luhr, Daniel Schneider, and Kristen Harknett. "Parenting without Predictability: Precarious Schedules, Parental Strain, and Work-Life Conflict." RSF: The Russell Sage Foundation Journal of the Social Sciences. Volume number (Issue number): Page range. DOI:

Mihaila, Iulia and Sigan L. Hartley (2018). "Parental sleep quality and behavior problems of children with autism." Autism 22(3): 236-244.

Morduch, Jonathan and Rachel Schneider (2017). The financial diaries: How American families cope in a world of uncertainty. Princeton, NJ, Princeton University Press.

Muhib, Farazana B., Lillian S. Lin, Ann Stueve, Robin L. Miller, Wesley L. Ford, Wayne D. Johnson, Philip J. Smith and Community Intervention Trial for Youth Study Team (2001). "A venue-based method for sampling hard-to-reach populations." Public health reports 116(1 suppl): 216-222.

Park, Eliza M., Samantha Meltzer-Brody and Robert Stickgold (2013). "Poor sleep maintenance and subjective sleep quality are associated with postpartum maternal depression symptom severity." Archives of women's mental health 16(6): 539-547.

Ryan, Richard M., Jessey H. Bernstein and Kirk W. Brown (2010). "Weekends, Work, and Well-Being: Psychological Need Satisfactions and Day of the Week Effects on Mood, Vitality, and Physical Symptoms." Journal of Social and Clinical Psychology 29(1): 95-122.

Schneider, Daniel and Kristen Harknett (2019). "Consequences of Routine Work-Schedule Instability for Worker Health and Well-Being." American Sociological Review 84(1): 82-114.

Schwartz, Ari, Michael Wasser, Merrit Gillard and Michael Paarlberg (2015). Unpredictable, unsustainable: The impact of employers' scheduling practices in D.C. D.C. Jobs with Justice.

Shrout, Patrick E., Niall Bolger, Masumi Iida, Christopher Burke, Marci E. J. Gleason and Sean P. Lane (2010). "Acute stress: results from a diary study of bar exam preparation." Support Processes in Intimate Relationships. Kieran T. Sullivan and Joanne Davila. New York, Oxford University Press: 175-199.

Sprajcer, Madeline, Sarah M. Jay, Grace E. Vincent, Andrew Vakulin, Leon Lack and Sally A. Ferguson (2018). "Uncertain call likelihood negatively affects sleep and next-day cognitive performance while oncall in a laboratory environment." Chronobiology international 35(6): 838-848.

Williams, Joan C., Susan J. Lambert, Saravanan Kesavan, Peter J. Fugiel, Lori A. Ospina, Erin D. Rapoport, Meghan Jarpe, Dylan Bellisle, Pradeep Pandem, Lisa McCorkell and Sarah Adler-Milstein (2018). Stable Scheduling Increases Productivity and Sales. The Kenan Institute of Private Enterprise. 


\begin{tabular}{|c|c|c|c|c|}
\hline Respondent Characteristics & Overall & $\begin{array}{c}\text { No } \\
\text { treatment } \\
\text { job (C) }\end{array}$ & $\begin{array}{c}1+ \\
\text { treatment } \\
\text { job }(\mathrm{T})\end{array}$ & $\begin{array}{c}\text { Significant } \\
\text { difference } \\
\text { between } \\
T \text { and C }\end{array}$ \\
\hline Age (mean) & 29.6 & 30.9 & 28.45 & + \\
\hline Female & $86.2 \%$ & $86.7 \%$ & $85.4 \%$ & \\
\hline Education (mean years) & 11.7 & 12.2 & 11.4 & \\
\hline Has 12 or more years of education & $73.4 \%$ & $76.9 \%$ & $71.8 \%$ & \\
\hline Age at First Birth (mean) & 23.5 & 23.8 & 23.1 & \\
\hline Ever married & $28.2 \%$ & $36.4 \%$ & $20.0 \%$ & + \\
\hline \multicolumn{5}{|l|}{ Race/Ethnicity: } \\
\hline Hispanic (of any race) & $30.6 \%$ & $31.8 \%$ & $30.0 \%$ & \\
\hline African-American (non-Hispanic) & $44.7 \%$ & $43.2 \%$ & $45.0 \%$ & \\
\hline Caucasian (non-Hispanic) & $8.2 \%$ & $4.5 \%$ & $12.5 \%$ & \\
\hline Asian (non-Hispanic) & $8.2 \%$ & $11.4 \%$ & $5.0 \%$ & \\
\hline Native American (non-Hispanic) & $1.2 \%$ & $0.0 \%$ & $2.5 \%$ & \\
\hline Multi-racial (non-Hispanic) & $7.1 \%$ & $9.1 \%$ & $5.0 \%$ & \\
\hline \multicolumn{5}{|l|}{ Household Characteristics } \\
\hline Number of children (mean) & 1.80 & 1.84 & 1.77 & \\
\hline Respondent currently married or living w/ partner & $58.3 \%$ & $61.4 \%$ & $56.4 \%$ & \\
\hline Respondent lives with a parent & $21.4 \%$ & $23.3 \%$ & $17.5 \%$ & \\
\hline \multicolumn{5}{|l|}{ Focal Child Characteristics } \\
\hline Age (mean) & 3.6 & 4.0 & 3.2 & \\
\hline Female & $54.4 \%$ & $61.4 \%$ & $44.1 \%$ & \\
\hline \multicolumn{5}{|l|}{ Care arrangements: } \\
\hline enrolled in Head Start & $35.4 \%$ & $52.3 \%$ & $11.8 \%$ & $* *$ \\
\hline enrolled in daycare & $50.0 \%$ & $62.8 \%$ & $32.4 \%$ & $* *$ \\
\hline enrolled in afterschool & $17.9 \%$ & $20.9 \%$ & $14.7 \%$ & \\
\hline receives care from non-respondent parent & $46.8 \%$ & $39.5 \%$ & $55.9 \%$ & \\
\hline receives care from other relative & $40.0 \%$ & $26.2 \%$ & $59.4 \%$ & $* *$ \\
\hline Total hours of non-respondent care per week (mean) & 38.2 & 30.0 & 47.8 & $* *$ \\
\hline \multicolumn{5}{|l|}{ Work situation } \\
\hline at least one treatment job covered by FWO & $57.7 \%$ & $0.0 \%$ & $100.0 \%$ & \\
\hline \# of jobs held by respondent (mean) & 1.13 & 1.10 & 1.19 & \\
\hline Monthly household income (mean) & $\$ 2,795$ & $\$ 2,945$ & $\$ 2,633$ & \\
\hline \multicolumn{5}{|l|}{ Respondent Mental Health } \\
\hline Often or always found it difficult to relax & $26.3 \%$ & $23.3 \%$ & $31.3 \%$ & \\
\hline Often or always felt down-hearted or blue & $10.5 \%$ & $7.0 \%$ & $15.6 \%$ & \\
\hline \multicolumn{5}{|l|}{ Focal Child Mental Health } \\
\hline Often somewhat or very worried & $21.5 \%$ & $15.9 \%$ & $29.4 \%$ & \\
\hline Often somewhat or very unhappy, depressed, or tearful & $10.1 \%$ & $9.1 \%$ & $11.8 \%$ & \\
\hline
\end{tabular}

$N=78 ;+p<.10$ 
Table 2. Daily Outcomes Across Waves

\begin{tabular}{|c|c|c|c|c|c|}
\hline Person-job-days & Overall & $\frac{\stackrel{\text { Non- }}{\text { Hispanic }}}{\text { Black }}$ & $\frac{\stackrel{\text { Non- }}{\text { Hispanic }}}{\text { White }}$ & $\frac{\text { Non- }}{\frac{\text { Hispanic }}{\text { Asian- }}}$ & $\frac{\text { Hispanic }}{\text { (any race) }}$ \\
\hline Share with any schedule change & 0.106 & 0.105 & 0.078 & 0.173 & 0.100 \\
\hline Share with last minute change & $\begin{array}{c}(0.004) \\
0.700 \\
(0.003)\end{array}$ & $\begin{array}{c}(0.006) \\
0.073 \\
(0.005)\end{array}$ & $\begin{array}{c}(0.011) \\
0.047 \\
(0.009)\end{array}$ & $\begin{array}{c}(0.015) \\
0.086 \\
(0.011)\end{array}$ & $\begin{array}{c}(0.007) \\
0.076 \\
(0.006)\end{array}$ \\
\hline Share with achange in work hours & $\begin{array}{c}0.055 \\
(0.003)\end{array}$ & $\begin{array}{c}0.051 \\
(0.004)\end{array}$ & $\begin{array}{c}0.054 \\
(0.009)\end{array}$ & $\begin{array}{c}0.103 \\
(0.012)\end{array}$ & $\begin{array}{c}0.051 \\
(0.005)\end{array}$ \\
\hline Share with a cancelled shift & $\begin{array}{c}0.041 \\
(0.002)\end{array}$ & $\begin{array}{c}0.043 \\
(0.004)\end{array}$ & $\begin{array}{c}0.017 \\
(0.005)\end{array}$ & $\begin{array}{c}0.064 \\
(0.009)\end{array}$ & $\begin{array}{l}0.040 \\
(0.005)\end{array}$ \\
\hline Share with a surprise shift & $\begin{array}{c}0.010 \\
(0.001)\end{array}$ & $\begin{array}{c}0.012 \\
(0.002)\end{array}$ & $\begin{array}{c}0.007 \\
(0.003)\end{array}$ & $\begin{array}{c}0.006 \\
(0.003)\end{array}$ & $\begin{array}{c}0.010 \\
(0.002)\end{array}$ \\
\hline Share worked today & $\begin{array}{c}0.547 \\
(0.006)\end{array}$ & $\begin{array}{c}0.509 \\
(0.009)\end{array}$ & $\begin{array}{c}0.503 \\
(0.021)\end{array}$ & $\begin{array}{c}0.613 \\
(0.019)\end{array}$ & $\begin{array}{l}0.603 \\
(0.011)\end{array}$ \\
\hline $\begin{array}{l}\text { Mean hours worked on work days } \\
\text { standard deviation }\end{array}$ & $\begin{array}{c}7.12 \\
2.01 \\
(0.03)\end{array}$ & $\begin{array}{c}7.15 \\
2.02 \\
(0.05)\end{array}$ & $\begin{array}{c}7.39 \\
1.62 \\
(0.10)\end{array}$ & $\begin{array}{c}6.73 \\
2.00 \\
(0.10)\end{array}$ & $\begin{array}{c}7.17 \\
1.99 \\
(0.06)\end{array}$ \\
\hline $\begin{array}{l}\text { Mean hours worked including non-work days } \\
\text { standard deviation }\end{array}$ & $\begin{array}{c}3.83 \\
3.84 \\
(0.05)\end{array}$ & $\begin{array}{c}3.49 \\
3.84 \\
(0.07)\end{array}$ & $\begin{array}{c}3.70 \\
3.87 \\
(0.16)\end{array}$ & $\begin{array}{c}4.08 \\
3.64 \\
(0.14)\end{array}$ & $\begin{array}{c}4.11 \\
3.85 \\
(0.09)\end{array}$ \\
\hline$N$ & 6,945 & 3,107 & 575 & 671 & 1,875 \\
\hline \multicolumn{6}{|l|}{ Person-days } \\
\hline Share parent had negative mood & $\begin{array}{c}0.422 \\
(0.006)\end{array}$ & $\begin{array}{c}0.423 \\
(0.010)\end{array}$ & $\begin{array}{c}0.598 \\
(0.020)\end{array}$ & $\begin{array}{c}0.447 \\
(0.020)\end{array}$ & $\begin{array}{c}0.361 \\
(0.012)\end{array}$ \\
\hline Raw Sleep Difficulty (1-10 scale) (mean) & 2.9 & 2.8 & 3.8 & 2.6 & 2.8 \\
\hline standard deviation & $\begin{array}{c}2.21 \\
(0.03)\end{array}$ & $\begin{array}{c}2.2 \\
(0.04)\end{array}$ & $\begin{array}{c}1.92 \\
(0.08)\end{array}$ & $\begin{array}{c}1.45 \\
(0.06)\end{array}$ & $\begin{array}{c}2.48 \\
(0.06)\end{array}$ \\
\hline Share lost temper & $\begin{array}{c}0.092 \\
(0.004)\end{array}$ & $\begin{array}{c}0.097 \\
(0.006)\end{array}$ & $\begin{array}{c}0.078 \\
(0.011)\end{array}$ & $\begin{array}{c}0.113 \\
(0.013)\end{array}$ & $\begin{array}{c}0.093 \\
(0.007)\end{array}$ \\
\hline Share punished child & $\begin{array}{c}0.084 \\
(0.004)\end{array}$ & $\begin{array}{c}0.071 \\
(0.005)\end{array}$ & $\begin{array}{c}0.134 \\
(0.014)\end{array}$ & $\begin{array}{l}0.108 \\
(0.013)\end{array}$ & $\begin{array}{c}0.077 \\
(0.007)\end{array}$ \\
\hline $\begin{array}{l}\text { Share child was uncooperative most/all of the } \\
\text { day }\end{array}$ & $\begin{array}{c}0.139 \\
(0.004)\end{array}$ & $\begin{array}{c}0.159 \\
(0.007)\end{array}$ & $\begin{array}{c}0.137 \\
(0.014)\end{array}$ & $\begin{array}{l}0.187 \\
(0.016)\end{array}$ & $\begin{array}{c}0.099 \\
(0.007)\end{array}$ \\
\hline Share child was worried most/all of the day & $\begin{array}{c}0.054 \\
(0.003)\end{array}$ & $\begin{array}{c}0.063 \\
(0.005)\end{array}$ & $\begin{array}{c}0.045 \\
(0.009)\end{array}$ & $\begin{array}{c}0.087 \\
(0.011)\end{array}$ & $\begin{array}{c}0.032 \\
(0.004)\end{array}$ \\
\hline$N$ & 6,059 & 2,610 & 575 & 611 & 1,653 \\
\hline
\end{tabular}

Standard errors in parentheses. 
Ananat, Gassman-Pines, \& Fitz-Henley II - Effects of Emeryville Fair Workweek Ordinance - 30

Table 3. Effect of Emeryville Fair Workweek Ordinance on daily work schedule disruptions

\begin{tabular}{|c|c|c|c|}
\hline & $\begin{array}{c}\text { Wave } 3 \\
\text { only as } \\
\text { Post }\end{array}$ & $\begin{array}{c}\text { Waves } 2 \\
\text { and } 3 \text { as } \\
\text { Post }\end{array}$ & $\begin{array}{c}\text { Waves } 2 \\
\text { and } 3 \\
\text { unique } \\
\text { effects }\end{array}$ \\
\hline \multicolumn{4}{|c|}{ Outcome: Any schedule change } \\
\hline Policy impact ${ }^{\mathrm{a} b}$ & $\begin{array}{l}-0.037 \\
(0.029)\end{array}$ & $\begin{array}{c}-.042+ \\
(0.024)\end{array}$ & $\begin{array}{l}-0.025 \\
(0.028)\end{array}$ \\
\hline Wave 2 policy impact & & & $\begin{array}{c}-.055^{*} \\
(0.025)\end{array}$ \\
\hline \multicolumn{4}{|c|}{ Outcome: Last-minute schedule change } \\
\hline Policy impact ${ }^{\mathrm{a} b}$ & $\begin{array}{l}-0.032 \\
(0.022)\end{array}$ & $\begin{array}{c}-.034+ \\
(0.019)\end{array}$ & $\begin{array}{l}-0.029 \\
(0.021)\end{array}$ \\
\hline Wave 2 policy impact & & & $\begin{array}{c}-.039+ \\
(0.020)\end{array}$ \\
\hline \multicolumn{4}{|c|}{ Outcome: Change in work hours } \\
\hline Policy impact ${ }^{\mathrm{a}} \mathrm{b}$ & $\begin{array}{l}-0.031 \\
(.022)\end{array}$ & $\begin{array}{l}-0.027 \\
(.021)\end{array}$ & $\begin{array}{l}-0.021 \\
(.024)\end{array}$ \\
\hline Wave 2 policy impact & & & $\begin{array}{l}-0.031 \\
(.022)\end{array}$ \\
\hline \multicolumn{4}{|l|}{ Outcome: Canceled shift } \\
\hline Policy impact ${ }^{\mathrm{a}} \mathrm{b}$ & $\begin{array}{l}0.012 \\
(.015)\end{array}$ & $\begin{array}{l}0.002 \\
(.011)\end{array}$ & $\begin{array}{l}0.014 \\
(.014)\end{array}$ \\
\hline Wave 2 policy impact & & & $\begin{array}{l}-0.008 \\
(.012)\end{array}$ \\
\hline \multicolumn{4}{|l|}{ Outcome: Surprise shift } \\
\hline Policy impact ${ }^{\mathrm{b}}$ & $\begin{array}{l}-.019 * \\
(.007)\end{array}$ & $\begin{array}{l}-.017^{*} \\
(.007)\end{array}$ & $\begin{array}{l}-.019 * \\
(.007)\end{array}$ \\
\hline Wave 2 policy impact & & & $\begin{array}{l}-.016^{*} \\
(.008)\end{array}$ \\
\hline
\end{tabular}

\footnotetext{
${ }^{a}$ Treatment $x$ Wave 3 for Models 1 and 3

${ }^{b}$ Treatment $x$ post (Wave 2 and 3 ) for Model 2

$+p<.10 ; * p<.05$
} 
Ananat, Gassman-Pines, \& Fitz-Henley II - Effects of Emeryville Fair Workweek Ordinance - 31

Table 4. Effect of Emeryville Fair Workweek Ordinance on daily work and work hours

\begin{tabular}{|c|c|c|c|}
\hline & & Model 2: & \\
\hline & $\begin{array}{l}\text { Model 1: } \\
\text { Wave } 3 \text { only } \\
\text { as Post }\end{array}$ & $\begin{array}{c}\text { Waves } 2 \\
\text { and } 3 \text { as } \\
\text { Post }\end{array}$ & $\begin{array}{c}\text { Model } 3 \text { : } \\
\text { Waves } 2 \text { and } 3 \\
\text { unique effects }\end{array}$ \\
\hline Outcome: Worked toda & & & \\
\hline Policy impact ${ }^{\mathrm{a} b}$ & $-.128 *$ & $-.098 *$ & $-.118+$ \\
\hline & $(.064)$ & $(.048)$ & $(.058)$ \\
\hline Wave 2 policy impact & & & -0.082 \\
\hline & & & $(.052)$ \\
\hline Outcome: Hours worked & & & \\
\hline Policy impact ${ }^{a b}$ & $.509 *$ & 0.185 & $.393+$ \\
\hline & $(.250)$ & $(.254)$ & $(.233)$ \\
\hline Wave 2 policy impact & & & 0.009 \\
\hline & & & $(.316)$ \\
\hline Outcome: Hours workes & & & \\
\hline Policy impact ${ }^{\mathrm{a} b}$ & -0.474 & -0.433 & -0.381 \\
\hline & $(.515)$ & $(.401)$ & (.479) \\
\hline Wave 2 policy impact & & & -0.475 \\
\hline & & & $(.437)$ \\
\hline Outcome: Hours worke & & & \\
\hline non-work days) & & & \\
\hline Policy impact ${ }^{a b}$ & -0.698 & 0.441 & -0.623 \\
\hline & $(.743)$ & $(.666)$ & $(.734)$ \\
\hline Wave 2 policy impact & & & $1.372+$ \\
\hline & & & $(.818)$ \\
\hline
\end{tabular}

a Treatment $x$ Wave 3 for Models 1 and 3

${ }^{\mathrm{b}}$ Treatment $x$ post (Wave 2 and 3 ) for Model 2

$+p<.10 ; * p<.05$ 
Ananat, Gassman-Pines, \& Fitz-Henley II - Effects of Emeryville Fair Workweek Ordinance - 32

Table 5. Effect of Emeryville Fair Workweek Ordinance on daily family well-being

\begin{tabular}{|c|c|c|c|c|c|c|}
\hline \multirow[b]{2}{*}{ Parental well-being } & $\begin{array}{c}\text { Wave } 3 \\
\text { only as } \\
\text { Post }\end{array}$ & $\begin{array}{c}\text { Waves } 2 \\
\text { and } 3 \text { as } \\
\text { Post }\end{array}$ & $\begin{array}{c}\text { Waves } 2 \\
\text { and } 3 \\
\text { unique } \\
\text { effects }\end{array}$ & $\begin{array}{c}\text { Wave } 3 \\
\text { only as } \\
\text { Post }\end{array}$ & $\begin{array}{c}\text { Waves } 2 \\
\text { and } 3 \text { as } \\
\text { Post }\end{array}$ & $\begin{array}{c}\text { Waves } 2 \\
\text { and } 3 \\
\text { unique } \\
\text { effects }\end{array}$ \\
\hline & \multicolumn{3}{|c|}{ Outcome: Parent negative mood } & \multicolumn{3}{|c|}{ Outcome: Parent sleep difficulty } \\
\hline \multirow[t]{2}{*}{ Policy impact ${ }^{\mathrm{a} b}$} & -3.740 & -0.869 & -3.839 & $-.281^{*}$ & -0.196 & $-.282^{*}$ \\
\hline & $(5.397)$ & $(4.172)$ & $(5.228)$ & $(0.137)$ & $(0.124)$ & $(0.136)$ \\
\hline \multirow[t]{2}{*}{ Wave 2 policy impact } & & & 1.738 & & & -0.118 \\
\hline & & & (3.991) & & & $(0.142)$ \\
\hline Parenting behaviors & \multicolumn{3}{|c|}{ Outcome: Lost temper } & \multicolumn{3}{|c|}{ Outcome: Punished child } \\
\hline \multirow[t]{2}{*}{ Policy impact ${ }^{a b}$} & -2.306 & -1.693 & -2.564 & 2.507 & 1.820 & 1.864 \\
\hline & $(1.976)$ & $(1.684)$ & $(1.886)$ & (2.319) & $(1.846)$ & $(2.269)$ \\
\hline \multirow[t]{2}{*}{ Wave 2 policy impact } & & & -1.031 & & & 1.699 \\
\hline & & & $(2.216)$ & & & $(1.999)$ \\
\hline Child well-being & \multicolumn{3}{|c|}{ Outcome: Child uncooperative } & \multicolumn{3}{|c|}{ Outcome: Child worried } \\
\hline \multirow[t]{2}{*}{ Policy impact ${ }^{\mathrm{a} b}$} & -1.328 & -2.168 & -2.014 & 0.893 & 0.087 & 0.211 \\
\hline & (4.319) & $(3.242)$ & $(4.161)$ & $(2.383)$ & $(1.878)$ & $(2.355)$ \\
\hline \multirow[t]{2}{*}{ Wave 2 policy impact } & & & -2.539 & & & -0.147 \\
\hline & & & (3.166) & & & $(1.811)$ \\
\hline
\end{tabular}

\footnotetext{
a Treatment $x$ Wave 3 for Models 1 and 3

${ }^{\mathrm{b}}$ Treatment $\mathrm{x}$ post (Wave 2 and 3 ) for Model 2

$+p<.10 ; * p<.05$
} 
Table 6. Intent-to-Treat Analysis of Effect of Emeryville Fair Workweek Ordinance on daily work schedule disruptions

\begin{tabular}{|c|c|c|c|}
\hline & $\begin{array}{c}\text { Wave } 3 \text { only } \\
\text { as Post }\end{array}$ & $\begin{array}{c}\text { Waves } 2 \text { and } \\
3 \text { as Post }\end{array}$ & $\begin{array}{l}\text { Waves } 2 \text { and } 3 \\
\text { unique effects }\end{array}$ \\
\hline \multicolumn{4}{|c|}{ Outcome: Any schedule change } \\
\hline Policy impact ${ }^{\mathrm{ab}}$ & $\begin{array}{l}-0.129 * \\
(0.064)\end{array}$ & $\begin{array}{c}-.042+ \\
(0.024)\end{array}$ & $\begin{array}{l}-0.025 \\
(0.028)\end{array}$ \\
\hline Wave 2 policy impact & & & $\begin{array}{c}-.055^{*} \\
(0.025)\end{array}$ \\
\hline \multicolumn{4}{|c|}{ Outcome: Last-minute schedule change } \\
\hline Policy impact ${ }^{a b}$ & $\begin{array}{l}-0.032 \\
(0.022)\end{array}$ & $\begin{array}{l}-.034+ \\
(0.019)\end{array}$ & $\begin{array}{l}-0.029 \\
(0.021)\end{array}$ \\
\hline Wave 2 policy impact & & & $\begin{array}{r}-.039+ \\
(0.020)\end{array}$ \\
\hline \multicolumn{4}{|c|}{ Outcome: Change in work hours } \\
\hline Policy impact ${ }^{\mathrm{b}}$ & $\begin{array}{l}-0.031 \\
(.022)\end{array}$ & $\begin{array}{l}-0.027 \\
(.021)\end{array}$ & $\begin{array}{l}-0.021 \\
(.024)\end{array}$ \\
\hline Wave 2 policy impact & & & $\begin{array}{l}-0.031 \\
(.022)\end{array}$ \\
\hline \multicolumn{4}{|l|}{ Outcome: Canceled shift } \\
\hline Policy impact ${ }^{\mathrm{a} b}$ & $\begin{array}{l}0.012 \\
(.015)\end{array}$ & $\begin{array}{l}0.002 \\
(.011)\end{array}$ & $\begin{array}{l}0.014 \\
(.014)\end{array}$ \\
\hline Wave 2 policy impact & & & $\begin{array}{l}-0.008 \\
(.012)\end{array}$ \\
\hline \multicolumn{4}{|l|}{ Outcome: Surprise shift } \\
\hline Policy impact ${ }^{\mathrm{ab}}$ & $\begin{array}{l}-.019^{*} \\
(.007)\end{array}$ & $\begin{array}{l}-.017^{*} \\
(.007)\end{array}$ & $\begin{array}{l}-.019 * \\
(.007)\end{array}$ \\
\hline Wave 2 policy impact & & & $\begin{array}{l}-.016^{*} \\
(.008) \\
\end{array}$ \\
\hline
\end{tabular}

${ }^{a}$ Treatment $x$ Wave 3 for Models 1 and 3

${ }^{\mathrm{b}}$ Treatment $x$ post (Wave 2 and 3 ) for Model

2

$+p<.10 ; * p .05$ 
Table 7. Intent-to-Treat Analysis of Effect of Emeryville Fair Workweek Ordinance on daily work and work hours

\begin{tabular}{|c|c|c|c|}
\hline & $\begin{array}{c}\text { Model 1: } \\
\text { Wave } 3 \text { only } \\
\text { as Post }\end{array}$ & $\begin{array}{c}\text { Model 2: } \\
\text { Waves } 2 \\
\text { and } 3 \text { as } \\
\text { Post }\end{array}$ & $\begin{array}{c}\text { Model 3: } \\
\text { Waves } 2 \text { and } 3 \\
\text { unique effects }\end{array}$ \\
\hline \multicolumn{4}{|l|}{ Outcome: Worked today } \\
\hline Policy impact ${ }^{\mathrm{b}}$ & $\begin{array}{l}-.129 * \\
(.064)\end{array}$ & $\begin{array}{l}-.098^{*} \\
(.048)\end{array}$ & $\begin{array}{l}-.118+ \\
(.058)\end{array}$ \\
\hline Wave 2 policy impact & & & $\begin{array}{r}-0.082 \\
(.052)\end{array}$ \\
\hline \multicolumn{4}{|c|}{ Outcome: Hours worked on work days } \\
\hline Policy impact ${ }^{\mathrm{a} b}$ & $\begin{array}{c}.509 * \\
(.250)\end{array}$ & $\begin{array}{l}0.185 \\
(.254)\end{array}$ & $\begin{array}{c}.393+ \\
(.233)\end{array}$ \\
\hline Wave 2 policy impact & & & $\begin{array}{l}0.009 \\
(.316)\end{array}$ \\
\hline \multicolumn{4}{|c|}{ Outcome: Hours worked including non-workdays } \\
\hline Policy impact ${ }^{\mathrm{a} b}$ & $\begin{array}{r}-0.474 \\
(.515)\end{array}$ & $\begin{array}{r}-0.433 \\
(.401)\end{array}$ & $\begin{array}{r}-0.381 \\
(.479)\end{array}$ \\
\hline Wave 2 policy impact & & & $\begin{array}{r}-0.475 \\
(.437)\end{array}$ \\
\hline \multicolumn{4}{|c|}{$\begin{array}{l}\text { Outcome: Hours worked across all jobs (including } \\
\text { non-work days) }\end{array}$} \\
\hline Policy impact ${ }^{\mathrm{a} b}$ & $\begin{array}{r}-0.698 \\
(.743)\end{array}$ & $\begin{array}{l}0.441 \\
(.666)\end{array}$ & $\begin{array}{r}-0.623 \\
(.734)\end{array}$ \\
\hline Wave 2 policy impact & & & $\begin{array}{l}1.372+ \\
(.818)\end{array}$ \\
\hline
\end{tabular}

a Treatment $x$ Wave 3 for Models 1 and 3

${ }^{b}$ Treatment $x$ post (Wave 2 and 3) for Model 2

$+p<.10 ; * p<.05$ 
Ananat, Gassman-Pines, \& Fitz-Henley II - Effects of Emeryville Fair Workweek Ordinance - 35

Figure 1.
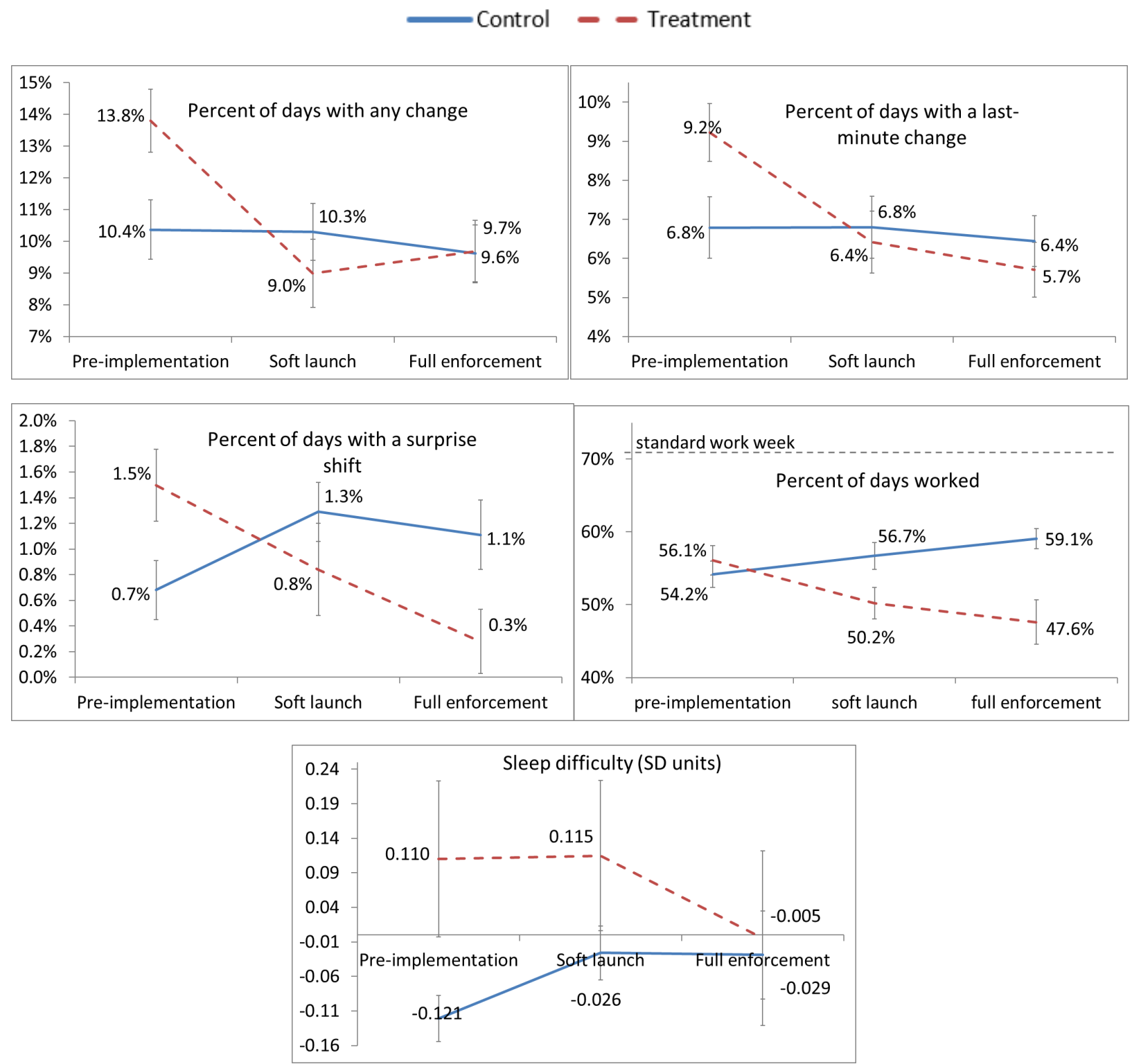